\title{
Factors associated with poor glycaemic control in type 2 diabetic elderly patients with mild cognitive impairment
}

\author{
Malgorzata Gorska-Ciebiada' ${ }^{1, A-F}$, Maciej Ciebiada ${ }^{2, A-F \oplus}$ \\ ${ }^{1}$ Department of Propaedeutics of Lifestyle Diseases, Medical University, Lodz, Poland \\ 2 Department of General and Oncological Pneumology, Medical University, Lodz, Poland \\ A - Research concept and design, B - Collection and/or assembly of data, C - Data analysis and interpretation, \\ $D$ - Writing the article, E-Critical revision of the article, $F$ - Final approval of article
}

Gorska-Ciebiada M, Ciebiada M. Factors associated with poor glycaemic control in type 2 diabetic elderly patients with mild cognitive impairment. J Pre-Clin Clin Res. 2019; 13(4): 143-149. doi: 10.26444/jpccr/114332

\begin{abstract}
I Abstract
Introduction and objective. Recently, data has indicated a higher incidence of mild cognitive impairment (MCl) in patients with diabetes. Old age is a risk factor for cognitive deterioration and dementia. The aim of the study was to find the factors associated with poor glycaemic control in type 2 diabetic elderly patients with $\mathrm{MCl}$.

Materials and method. A cross-sectional study was conducted on 87 diabetic patients with $\mathrm{MCl}$ in an outpatient clinic. All subjects were screened for $\mathrm{MCl}$ using the Montreal Cognitive Assessment (MoCA). Detailed medical history and collection of blood test samples were performed.

Results. $83.9 \%$ of participants had poor glycaemic control. A positive correlation was found between HbA1c level and number of visit to a doctor per year, number of co-morbidities, duration of T2DM, triglycerides and fasting glucose level; and a negative correlation between $\mathrm{HbA1c}$ level and years of education, $\mathrm{HDL}$ cholesterol level and MoCA score. The univariate logistic regression models revealed factors which are associated with poor glycemic control are: less years of education, higher no of visit to doctor per year, increased number of co-morbidities, presence of CVD, retinopathy, higher levels of triglycerides and fasting glucose, lower level of HDL cholesterol, lower MoCA score. Multivariable model revealed that higher plasma levels of fasting glucose and triglycerides are significant predictors.

Conclusions. There is a high prevalence of poor glycemic control patients among elderly diabetics with $\mathrm{MCl}$. Higher plasma levels of fasting glucose and triglycerides seems to be the most important predictors of poor glycemic control, however father larger studies are needed to elucidate these relationships.
\end{abstract}

\section{Key words}

diabetes mellitus, elderly, mild cognitive impairment

\section{INTRODUCTION}

Type 2 diabetes (T2DM) is one of the most common chronic diseases which can damage any organ in the body [1]. Recent studies have shown that the elderly with T2DM are at increased risk for developing micro- and macrovascular complications, as well as some psychiatric disorders such as cognitive dysfunction and dementia [2,3]. Mild cognitive impairment (MCI) is a transition stage between normal aging and dementia. The prevalence of MCI in elderly subjects is around 14-18\% [4]. Many hypotheses have been proposed about the mechanisms underlying diabetes and aged-related cognitive impairment or development of dementia. One of the theories underlies the participation of low-grade inflammation in diabetes and associated cognitive dysfunction $[5,6,7]$. Persistent chronic inflammation is linked to some common findings that share cognitive impairments and diabetes: lower hippocampal volumes, vascular changes in the brain and neurotransmitter deficits. Some large population studies have shown that an increase in the risk of cognitive decline over a two year period is

Address for correspondence: Malgorzata Gorska-Ciebiada, Department of Propaedeutics of Lifestyle Diseases Medical University of Lodz, 63 Jaracza Street, 90-251, Lodz, Poland

E-mail: magoca@poczta.onet.pl

Received:17.07.2019; accepted: 18.11.2019; first published: 31.12 .2019 connected to elevated levels of inflammatory markers, such as Interleukin 6 (IL-6) and CRP. In another study, the authors found higher levels of Tumour Necrosis Factor- $\alpha$ (TNF- $\alpha$ ), Interleukin-1 $\beta$ (IL-1 $\beta$ ), and Interleukin 12 in an MCI group, compared to those with normal cognitive function.

Inflammatory cytokines and other mediators were found in the cerebrospinal fluid and plasma in patients with Alzheimer's disease and also in senile plaques from brains with dementia. It has been hypothesized that in the state of peripheral insulin-resistance, insulin may cross the blood brain barrier and stimulate the overproduction of proinflammatory cy tokines $[5,6,7]$. Another theory discovered vascular pathology and blood-brain barrier disruption in cognitive and psychiatric complications of T2DM [8]. Some authors suggested that small vessel diseases in the brain (white matter lesions and lacunae) affect cognitive function in older diabetics without overt dementia or symptomatic stroke [8]. Independently, the causative roles for hyperglycaemia in cognitive dysfunction, $\mathrm{MCI}$ and dementia themselves can lead to the deterioration of glycaemic control, subsequently increasing the risk of the development of late complications of diabetes. Hyperglycaemia can act through many ways, e.g. increased formation of advanced glycation end products (AGEs), diacylglycerol activation of protein kinase C, polyol pathway activation, and increased glucose shunting in the hexosamine pathway. Effective glycaemic control is a crucial 
element of diabetes management. It prevents microvascular complications, such as lower limb amputations, blindness and end-stage renal disease. The association of glyaemic control with cognitive function is probably bidirectional. Some studies suggest that poorer glycaemic control leads to greater impairment in cognitive function and higher risk of dementia $[9,10]$. On the other hand, other authors suggest that deficits in cognitive functions lower the patients' ability to achieve good glycaemic control [11, 12].

With the rapidly growing number of older persons, diabetesassociated cognitive impairment is an increasingly bigger problem. Many elderly individuals often have numerous co-morbidities and geriatric problems which enable them to reach goals of therapy. Deficits in cognitive functions lead to problems in complex behaviours, such as solving, planning, attention, insight, organization and reasoning. The consequence of those impairments could be difficulties in the self-management of diabetes (medication compliance, glucose monitoring, dietary modification and regular physical activity). Although many healthcare providers screen their patients for cardiovascular risk factors, they very rarely evaluate diabetics for impairments in cognitive functions. As a result, many clinicians may be unaware that their patients have cognitive dysfunction. The authors of the current study hypothesize that cognitive dysfunction with some co-morbid conditions and risk factors may form a barrier to achieving or maintaining good glycaemic control among older adults with diabetes.

\section{OBJECTIVES}

The identification and possible modification of some risk factors could result in an establishment of better therapeutic interventions with goal achievement. Therefore, the aim of this study is to ascertain the factors associated with poor glycaemic control in type 2 diabetic elderly patients with MCI.

\section{MATERIALS AND METHOD}

Patients. The study population included 87 unselected elderly who attended an outpatient diabetology clinic, drawn from a study previously described [13]. A brief screening for recruitment was conducted by the researchers to identify potential participants. The inclusion criteria were: age 65 and over, diabetes type 2 diagnosed a minimum of one year earlier, and ability to understand and cooperate with study procedures. The exclusion criteria were: use of possible or known cognition-impairing drugs in the previous three months, diagnosed depression or dementia, constant alcohol or substance abuse, presence of neoplasm, severe visual, mobility, or motor coordination impairment, history of head trauma, inflammatory or infectious brain disease, severe neurological or psychiatric illness. The first part of visit included a complete physical examination, height and weight assessment, blood pressure measurements and morning blood drawn after a 10-12 hour overnight fast. The second part of visit took place in a private area in the clinic after eating a breakfast, followed by measurement of capillary glucose level to ensure that subjects were not hypoglycaemic at the time of cognitive testing. All participants underwent cognitive testing and completed a questionnaire describing baseline demographics.

Baseline characteristics, clinical evaluation and risk factor assessment. A standardized interview was performed to record demographic variables and possible risk factors. Body mass index $\left(\mathrm{BMI}=\right.$ weight $/$ height $\left.^{2}\left[\mathrm{Kg} / \mathrm{m}^{2}\right]\right)$ was calculated after weight and height measurements. The systolic and diastolic blood pressures $(\mathrm{mmHg}$ ) were measured after the participants had rested for five minutes in a sitting position. A detailed medical history of diabetes type 2 was taken and included: current treatment for diabetes and complications if present, diabetes duration, co-morbid diseases of the patient (hypertension, hyperlipidaemia, cardiovascular disease, gastrointestinal tract diseases, lung disease, cancer) and their treatment. Educational level was recorded in years of education. Diabetic vascular complications were assessed based on the existence of retinopathy, neuropathy, nephropathy, cardiovascular disease (CVD) and stroke. Hyperlipidaemia was defined as the use of any lipid lowering agent or an untreated serum LDL cholesterol level $2.6 \mathrm{mmol} / \mathrm{l}$ or/and triglycerides $1.7 \mathrm{mmol} / \mathrm{l}$. Hypertension was defined as either a history of hypertension or use of any antihypertensive treatments,

Blood collection. Fasting blood concentrations of glucose (FBG), glycosylated haemoglobin (HbAlc), total cholesterol, triglycerides, low-density lipoprotein cholesterol (LDL-C) and high-density lipoprotein cholesterol (HDL-C) were detected by standard enzymatic assays in a centralized laboratory.

Cognitive assessments. At the beginning of the study, 276 participants underwent the Montreal Cognitive Assessment (MoCA) to evaluate cognitive impairment [14], Katz Basic Activities of Daily Living (BADL) and Lawton Instrumental Activities of Daily Living (IADL) questionnaires were used to collect information on daily activities $[15,16] .87$ patients with MCI were evaluated and described in the presented study. The MoCA (version 8:1) test with cognitive domains: attention, immediate memory, delayed memory, visualspatial ability, executive function, language, calculation, abstraction, and orientation, were applied for a maximum total score of 30 . The normal MoCA score is $\geq 26$, with one point added if the subject has fewer than 12 years of formal education. The MoCA is recommended as the best tool to detect MCI in elderly patients with type 2 diabetes [17].

MCI was diagnosed according to the 2006 European Alzheimer's Disease Consortium criteria which are currently the available standard test $[18,19]$. These criteria included absence of dementia. The cut-off points for MoCA scores $(19 / 30)$ are recommended for the diagnosis of 'dementia' in epidemiological studies. Patients with score 19 and below were excluded from the study, classified as suffering from dementia and referred to a psychiatrist for further care.

The above-mentioned criteria also included the absence of major repercussions on daily life (measured in the current study by Katz BADL and Lawton IADL). Depressive symptoms were assessed using the Geriatric Depression Scale (GDS). Patients with scores 10 and above were excluded from the study group as having depressive symptomatology.

Groups selection. According to the American Diabetes Association Recommendations, the participants were divided into two groups: 
Group 1 - poor glycaemic control (defined as HbAlc $\geq 7.0 \%$ ( $\geq 53 \mathrm{mmol} / \mathrm{mol}$ );

Group 2 - good glycaemic control (it was defined as HbAlc $<7.0 \%(<53 \mathrm{mmol} / \mathrm{mol})[20]$.

Ethics. Approval to undertake the study was granted by the independent Local Ethics Committee of Medical University in Lodz, and performed in accordance with the World Medical Association's Declaration of Helsinki and its later amendments. Each participant was assigned an identification number in order to maintain their anonymity. The purpose, nature, and potential risks of the experiments were fully explained to the subjects, who provided their written, informed consent prior to inclusion in the study.

Statistical methods. All data are presented as means \pm SD. Normality of distributions was assessed using the ShapiroWilk tests. Descriptive statistics for categorical variables were tested using the $\chi^{2}$, and continuous variables using the Student's $t$ or the Mann Whitney-U tests, whenever applicable. Simple logistic regression model was performed in order to select so-called independent factors which increase the selection risk of poor glycaemic control in type 2 diabetic elderly patients with MCI. Multivariable regression model was carried out in order to select the 'strongest' factor from the independent risk factors. To 'optimize' the multivariable model, a stepwise approach was used (backward elimination with Wald criteria). Odds ratios (OR) were computed and presented with a $95 \%$ interval of confidence (CI). A P value of less than 0.05 was considered statistically significant. Statistica 10.0 (StatSoft, Kraków, Poland,) was used for analysis.

\section{RESULTS}

General characteristics. The general characteristics of the study group are shown in Table 1 . According to the criteria mentioned above, $73(83.9 \%)$ subjects with poor glycaemic control (Group 1) and 14 (16.1\%) with good glycaemic control (Group 2) were selected. Elderly male T2DM patients with MCI and with poor glycaemic control significantly dominated, had fewer years of education, higher number of visit to doctor per year, co-morbidities, longer duration of diabetes, and diagnosed with cardiovascular disease, hyperlipidaemia, and retinopathy. There were no significant differences between the groups in age, marital status, place of residence, smoking habit, income, diabetes self-control, presence of stroke, hypertension, nephropathy, neuropathy, hypoglycaemia, type of treatment and family history of T2DM. There were no differences between groups considering other diseases and the treatment (Tab. 2).

Biochemical parameters, BMI and MoCA score. Statistical tests showed that patients with poor glycaemic control (Group 1) had significantly higher levels of HbAlc, triglycerides and fasting glucose, and a lower level of HDL cholesterol (Tab. 1). There were no significant differences between the groups in level of total cholesterol and LDL cholesterol ( $p>0.05)$. BMI and systolic and diastolic blood pressure were similar in both groups of participants. MoCa score was lower in Group 1.

Relationship of serum levels of HbAlc with other clinical and biochemical indicators. Table 3 shows the relationship between serum levels of HbAlc and other clinical and biochemical indicators in the group of diabetic elderly patients with MCI. A positive correlation was found between HbAlc level and the number of visits to a doctor per year, number of co-morbidities, duration of T2DM, triglycerides and fasting glucose level; and a negative correlation between HbA1c level and years of education, HDL cholesterol level and MoCA score.

Logistic regression models. Because many factors can influence the results, univariate logistic regression models were constructed, and finally a multivariable regression model to determine the factors associated with poor glycaemic control type 2 diabetic elderly patients with MCI. The independent variables entered in the model at step one were: demographic variables (age, gender, education), socio-economic variables, diabetes self-control factors, duration of diabetes, cardiovascular diseases (MI, angina, stroke), cardiovascular risk factors (BMI, smoking status, hiperlipidaemia, previous HA or use of HA drugs), microvascular complications, number of comorbid conditions, levels of total, LDL, HDL cholesterol, triglycerides, type of treatment, FBG, systolic and diastolic blood pressure and MoCA score.

Univariate logistic regression models. The models revealed the factors associated with poor glycaemic control: fewer years of education, higher numbrer of visit to a doctor per year, increased number of co-morbidities, presence of $\mathrm{CVD}$, retinopathy, higher levels of triglycerides and fasting glucose, lower level of HDL cholesterol, and lower MoCA score (Tab. 4).

The multivariable model revealed the predictors of poor glyacemic control in type 2 diabetic elderly patients with MCI: higher plasma levels of fasting glucose and higher levels of triglycerides (Tab. 5).

\section{DISCUSSION}

This study shows that $83.9 \%$ type 2 diabetic elderly patients with MCI have poor glycaemic control. This observation is novel in the Polish population, and the result is consistent with other studies which presented high associations between poor glycaemic control and cognitive impairment in diabetics worldwide [21, 22, 23]. Data from cross-sectional studies agree that a chronic hyperglycaemic state causes cognitive function deficit. In the ACCORD-MIND study, it was observed that a $1 \%$ higher $\mathrm{A} 1 \mathrm{C}$ value was associated with a significantly lower Mini-Mental State Examination (MMSE) score, Digit Symbol Substitution Test (DSST) score, and worse score on the Stroop Test [24]. In another study of elderly diabetic subjects, it was observed that baseline HbAlc level was an independent factor for functional impairment, as indicated by Stroop test, DSST, and word recall performance [25]. Similarly, in the current study, a negative correlation was found between HbAlc level and MoCA score.

A longitudinal prospective study showed a fourfold increase in cognitive impairment in subjects with $\mathrm{HbAlc}$ $>7 \%$, compared with those with HbAlc $\leq 7 \%$ [26]; however, other studies have shown that HbAlc level was not a predictive factor for cognitive impairment [27]. In a recently published cross-sectional study performed in a primary 
Table 1. General characteristics of type 2 diabetic elderly patients with $\mathrm{MCl}$

\begin{tabular}{|c|c|c|c|c|c|}
\hline & All subjects & Group 1 & Group 2 & $x^{2} / z$ & $P$ value \\
\hline No. of patients & 87 & 73 & 14 & & \\
\hline Age (years) & $75.7 \pm 4.6$ & $76.1 \pm 4.6$ & $73.7 \pm 4.4$ & 1.5 & 0.12 \\
\hline Gender: female/male* & $53 / 34$ & $41 / 32$ & $12 / 2$ & 4.31 & 0.037 \\
\hline Education - years* & $9.7 \pm 1.8$ & $9.5 \pm 1.6$ & $11.0 \pm 2.4$ & -2.41 & 0.008 \\
\hline Single/married & $45 / 42$ & $38 / 35$ & $7 / 7$ & 0.02 & 0.88 \\
\hline Urban area/rural area & $61 / 26$ & $51 / 22$ & $10 / 4$ & 0.01 & 0.91 \\
\hline Smoked tobacco regularly & $26(29.8 \%)$ & $21(28.7 \%)$ & $5(35.7 \%)$ & 0.27 & 0.6 \\
\hline Low income & $57(65.5 \%)$ & $48(65.7 \%)$ & $9(64.2 \%)$ & 0.01 & 0.92 \\
\hline Poor control of diet (\%) & $44(50.6 \%)$ & $37(50.7 \%)$ & $7(50.0 \%)$ & 0.2 & 0.65 \\
\hline Lack of physical activity (\%) & $56(64.3 \%)$ & $47(64.3 \%)$ & $9(64.2 \%)$ & 2.04 & 0.15 \\
\hline Poor self-monitoring of blood glucose & $13(14.9 \%)$ & $11(15.1 \%)$ & $2(14.2 \%)$ & 0.13 & 0.72 \\
\hline Poor self-measurement of blood pressure & $20(22.9 \%)$ & $17(23.4 \%)$ & $3(21.4 \%)$ & 0.18 & 0.67 \\
\hline Poor self-control of foot & $18(20.6 \%)$ & $15(20.5 \%)$ & $3(21.4 \%)$ & 0.44 & 0.51 \\
\hline No. of visits to Doctor per year* & $3.12 \pm 1.1$ & $3.3 \pm 1.0$ & $2.36 \pm 1.1$ & 2.77 & 0.003 \\
\hline Duration of DM2 (years)* & $11.25 \pm 6.29$ & $11.8 \pm 5.9$ & $8.5 \pm 7.3$ & 2.48 & 0.01 \\
\hline Previous CVD* & $71(81.6 \%)$ & $63(86.3 \%)$ & $8(57.1 \%)$ & 6.65 & 0.009 \\
\hline Stroke & $7(8.04 \%)$ & $6(8.2 \%)$ & $1(7.1 \%)$ & 0.02 & 0.89 \\
\hline Previous HA or use of HA drugs & 80 (91.9\%) & $67(91.7 \%)$ & $13(92.8 \%)$ & 0.51 & 0.35 \\
\hline Hiperlipidaemia* & 80 (91.9\%) & $69(94.5 \%)$ & $11(78.5 \%)$ & 4.04 & 0.04 \\
\hline Retinopathy* & $61(70.1 \%)$ & $56(76.7 \%)$ & $5(35.7 \%)$ & 9.42 & 0.002 \\
\hline Nephropathy & $43(49.4 \%)$ & $38(52 \%)$ & $5(35.7 \%)$ & 1.25 & 0.26 \\
\hline Neuropathy & $20(22.9 \%)$ & $17(23.3 \%)$ & $3(21.4 \%)$ & 0.02 & 0.87 \\
\hline Hypoglycaemia & $60(68.9 \%)$ & $53(72.6 \%)$ & $7(50 \%)$ & 2.8 & 0.09 \\
\hline Insulin & $42(48.3 \%)$ & $38(52.1 \%)$ & $4(28.6 \%)$ & 2.59 & 0.11 \\
\hline OAD & $70(80.6 \%)$ & $57(78.1 \%)$ & $13(92.8 \%)$ & 3.7 & 0.05 \\
\hline Family history of diabetes & $39(44.8 \%)$ & $34(46.5 \%)$ & $5(35.7 \%)$ & 0.56 & 0.45 \\
\hline Co-morbidity (n)* & $7.07 \pm 3.22$ & $7.5 \pm 3.1$ & $5.07 \pm 3.0$ & 2.56 & 0.01 \\
\hline HbA1c (\%)* & $7.73 \pm 0.71$ & $7.96 \pm 0.52$ & $6.55 \pm 0.3$ & 5.89 & $<0.001$ \\
\hline $\mathrm{CHOL}(\mathrm{mmol} / \mathrm{l})$ & $4.8 \pm 1.02$ & $4.8 \pm 0.97$ & $4.8 \pm 1.32$ & 0.29 & 0.76 \\
\hline $\mathrm{LDL}(\mathrm{mmol} / \mathrm{l})$ & $2.79 \pm 0.75$ & $2.82 \pm 0.74$ & $2.66 \pm 0.91$ & 0.69 & 0.48 \\
\hline TG $(\mathrm{mmol} / \mathrm{l})^{*}$ & $2.15 \pm 0.54$ & $2.27 \pm 0.41$ & $1.55 \pm 0.73$ & 2.96 & 0.003 \\
\hline $\mathrm{HDL}(\mathrm{mmol} / \mathrm{l})^{*}$ & $1.07 \pm 0.28$ & $1.02 \pm 0.22$ & $1.31 \pm 0.43$ & -2.6 & 0.009 \\
\hline BMI (kg/m2) & $30.4 \pm 3.59$ & $30.5 \pm 3.55$ & $30.1 \pm 3.9$ & 0.26 & 0.79 \\
\hline Systolic blood pressure (mm Hg) & $136.5 \pm 16.4$ & $137.7 \pm 16.5$ & $130.1 \pm 14.8$ & 1.5 & 0.11 \\
\hline Diastolic blood pressure $(\mathrm{mm} \mathrm{Hg})$ & $75.1 \pm 8.0$ & $74.9 \pm 8.3$ & $76.07 \pm 7.3$ & -0.42 & 0.67 \\
\hline \multirow[t]{2}{*}{ Fasting plasma glucose (mmol/l)* } & $129.8 \pm 27.2$ & $135.8 \pm 24.4$ & $98.4 \pm 18.2$ & 4.64 & $<0.001$ \\
\hline & $21.6 \pm 1.5$ & $21.2 \pm 1.32$ & $22.4 \pm 1.69$ & -2.33 & 0.01 \\
\hline
\end{tabular}

${ }^{*} \mathrm{p}<0.05$ comparing participants with good control of diabetes with those with poor control.

Values are expressed by mean \pm SD or frequency; Student $t$ test, Mann-Whitney $U$ test, or $x^{2}$ test was used to test for significant differences.

Group 1 - Poor glycaemic control HbA1c $\geq 7 \%$; Group 2-Good glycaemic control HbA1c<7\%; DM2 - diabetes type 2; BMI-body mass index; TC-serum total cholesterol; LDL-low density lipoprotein cholesterol; TG - triglyceride; HDL - high-density lipoprotein cholesterol; OAD- oral anti-diabetic drug; CVD - cardiovascular disease; HA- hypertension; MoCA - Montreal Cognitive Assessment.

care centre, Grober et al. found that $61 \%$ of adults age 65 or older with a diagnosis of diabetes, had inadequately controlled (HbAlc $\geq 7 \%$ ) diabetes [28]. Their results confirmed that both memory impairment and executive dysfunction would predict inadequate glycaemic control. The authors suggested that cognitive dysfunction may interfere with diabetes management, and that inadequate diabetic control may contribute to cognitive dysfunction.

Poor glycaemic control may negatively affect cognitive function through an increase in oxidative stress. The overproduction of superoxide induces subsequent nitrosative stress with the generation of metabolic derivatives, such as peroxynitrite and nitrotyrosine. These toxic substances can damage neurons by direct neurotoxic effect which can lead to a decline in cognitive performance.

In the current study it was found that the T2DM group of elderly patients with MCI and with poor glycaemic control had a significantly higher proportion of males, with fewer years of education, a higher number of visits to doctor per year, co-morbidities, longer duration of diabetes. Additionally, many of them were diagnosed with cardiovascular disease, hyperlipidaemia and retinopathy.

Univariate logistic regression models revealed the factors associated with poor glycaemic control: fewer years of 
Table 2. Other diseases and treatment in type 2 diabetic elderly patients with $\mathrm{MCl}$

\begin{tabular}{|c|c|c|c|c|c|}
\hline & All subjects & Group 1 & Group 2 & $x^{2}$ & $P$ value \\
\hline No. of patients & 87 & 73 & 14 & & \\
\hline $\begin{array}{l}\text { Other diseases: } \\
\text { Lung disease (\%) }\end{array}$ & $15(17.2 \%)$ & 14 (19.2\%) & 1 (7.14\%) & 1.19 & 0.27 \\
\hline Atrial fibrillation (\%) & $21(24.1 \%)$ & $19(26.0 \%)$ & $2(14.3 \%)$ & 0.88 & 0.35 \\
\hline Heart failure (\%) & $23(26.4 \%)$ & $22(30.1 \%)$ & 1 (7.14\%) & 3.19 & 0.07 \\
\hline $\begin{array}{l}\text { Gastrointerstinal tract } \\
\text { disease (\%) }\end{array}$ & 42 (48.3\%) & $37(50.6 \%)$ & $5(35.7 \%)$ & 1.05 & 0.3 \\
\hline Kidney disease (\%) & $22(25.3 \%)$ & $18(24.6 \%)$ & $4(28.6 \%)$ & 0.1 & 0.75 \\
\hline Thyroid diasease (\%) & $27(31.0 \%)$ & $25(34.2 \%)$ & $2(14.3 \%)$ & 2.19 & 0.13 \\
\hline $\begin{array}{l}\text { Other treatment: } \\
\text { Angiotensin-converting } \\
\text { enzyme inhibitors (\%) }\end{array}$ & 47 (54.0\%) & 39 (53.4\%) & $8(57.1 \%)$ & 0.07 & 0.79 \\
\hline $\begin{array}{l}\text { Angiotensin II receptor } \\
\text { blockers (\%) }\end{array}$ & 34 (39.1\%) & $28(38.4 \%)$ & $6(42.8 \%)$ & 0.1 & 0.75 \\
\hline Diuretics (\%) & 34 (39.1\%) & 31 (42.4\%) & $3(21.4 \%)$ & 2.18 & 0.13 \\
\hline $\begin{array}{l}\text { Calcium channel } \\
\text { blockers (\%) }\end{array}$ & 29 (33.3\%) & $24(32.8 \%)$ & $5(35.7 \%)$ & 0.04 & 0.83 \\
\hline a1-Blockers (\%) & $11(12.6 \%)$ & $11(15.1 \%)$ & $0(0 \%)$ & 2.4 & 0.14 \\
\hline B-blockers (\%) & $63(72.4 \%)$ & 55 (75.3\%) & $8(57.1 \%)$ & 1.95 & 0.16 \\
\hline $\begin{array}{l}\text { Lipid-lowering } \\
\text { medications (\%) }\end{array}$ & $62(71.2 \%)$ & $53(72.6 \%)$ & $9(64.3 \%)$ & 0.4 & 0.52 \\
\hline
\end{tabular}

Table 3. Relationship of serum levels of HbA1c with other clinical and biochemical indicators in group of diabetic elderly patients with $\mathrm{MCl}$

\begin{tabular}{lcc}
\hline & $\mathbf{r}$ & $\mathbf{p}$ \\
\hline Age (years) & 0.19 & 0.07 \\
\hline Education - years* & -0.35 & 0.001 \\
\hline No. of visits to doctor per year* & 0.36 & 0.001 \\
\hline Duration of DM2 (years)* & 0.28 & 0.008 \\
\hline Co-morbidity $(\mathbf{n}) *$ & 0.34 & 0.001 \\
\hline CHOL $(\mathrm{mmol} / \mathrm{l})$ & 0.11 & 0.3 \\
\hline LDL $(\mathrm{mmol} / \mathrm{l})$ & 0.13 & 0.22 \\
\hline TG (mmol//)* & 0.41 & $<0.001$ \\
\hline HDL (mmol/l)* & -0.36 & 0.001 \\
\hline BMI (kg/m2) & 0.002 & 0.98 \\
\hline Systolic blood pressure $(\mathrm{mm} \mathrm{Hg})$ & -0.014 & 0.89 \\
\hline Diastolic blood pressure $(\mathrm{mm} \mathrm{Hg})$ & 0.006 & 0.95 \\
\hline Fasting plasma glucose $(\mathrm{mmol} / \mathrm{l})^{*}$ & 0.42 & $<0.001$ \\
\hline MoCA score* & -0.416 & $<0.001$ \\
\hline
\end{tabular}

* significance $-p<0.05$; $r$-correlation coefficient.

DM2 - diabetes type 2: BMI - body mass index. TC - serum total cholesterol

LDL - low density lipoprotein cholesterol; TG - triglyceride; HDL - high-density

lipoprotein cholesterol; MoCA - Montreal Cognitive Assessment.

Table 5. Factors associated with poor glycaemic control in type 2 diabetic elderly patients with $\mathrm{MCl}$ in multivariable logistic regression model

\begin{tabular}{lccccc}
\hline Variables analyzed & $B$ & SE of $B$ & $p$ value & OR & $95 \% \mathrm{Cl}$ \\
\hline Fasting plasma glucose $(\mathrm{mmol} /)^{*}$ & 0.07 & 0.02 & 0.003 & 1.08 & $1.02-1.14$ \\
\hline TG $\left(\mathrm{mmol} / \mathrm{l}^{*}\right.$ & 0.02 & 0.007 & 0.026 & 1.02 & $1.002-1.03$ \\
\hline
\end{tabular}

Cl-confidence intervalfor odds ratio; OR -0 dds ratio; ${ }^{*}$ signiffance, $p<0.05$

$\mathrm{Cl}$ - confidence interval for odds ratio; OR - odds ratio; * significance, $\mathrm{p}<0.05$
Table 4. Factors associated with poor glycaemic control in type 2 diabetic elderly patients with $\mathrm{MCl}$ in a simple logistic regression model

\begin{tabular}{|c|c|c|c|c|c|}
\hline Variables analyzed & B & $S E$ of $\beta$ & $p$ value & OR & $95 \% \mathrm{Cl}$ \\
\hline \multicolumn{6}{|l|}{ No. of patients } \\
\hline Age (years) & 0.1 & 0.06 & 0.09 & 1.11 & $0.98-1.26$ \\
\hline Gender: female & 1.4 & 0.7 & 0.051 & 0.2 & $0.04-1.02$ \\
\hline Education - years* & -0.43 & 0.17 & 0.01 & 0.64 & $0.46-0.91$ \\
\hline Single & 0.5 & 0.08 & 0.88 & 1.08 & $0.34-3.4$ \\
\hline Urban area & 0.6 & 0.07 & 0.91 & 0.92 & $0.26-3.27$ \\
\hline Smoked tobacco regularly & 0.61 & 0.3 & 0.61 & 0.72 & $0.21-2.42$ \\
\hline Low income & 0.06 & 0.6 & 0.91 & 1.06 & $0.34-3.5$ \\
\hline Poor control of diet & 0.58 & 0.2 & 0.65 & 0.77 & $0.24-2.44$ \\
\hline Lack of physical activity & 0.8 & 0.6 & 0.16 & 0.4 & $0.1-1.4$ \\
\hline $\begin{array}{l}\text { Poor self-monitoring of blood } \\
\text { glucose }\end{array}$ & 0.8 & 0.31 & 0.72 & 0.72 & $0.14-3.9$ \\
\hline $\begin{array}{l}\text { Poor self-measurement of blood } \\
\text { pressure }\end{array}$ & 0.6 & 0.2 & 0.67 & 0.75 & $0.2-2.7$ \\
\hline Poor self-control of foot & 0.43 & 0.06 & 0.51 & 0.64 & $0.18-2.35$ \\
\hline No. of visits to Doctor per year* & 0.79 & 0.2 & 0.006 & 2.21 & $1.24-3.92$ \\
\hline Duration of DM2 (years) & 0.12 & 0.07 & 0.07 & 1.13 & $0.98-1.3$ \\
\hline Previous CVD* & 1.53 & 0.68 & 0.01 & 4.73 & $1.35-16.5$ \\
\hline Stroke & 1.12 & 0.15 & 0.89 & 1.16 & $0.13-10.4$ \\
\hline Previous HA or use of HA drugs & 1.62 & 0.5 & 0.06 & 1.23 & $1.12-1.35$ \\
\hline Hiperlipidaemia & 1.54 & 0.83 & 0.06 & 4.7 & $0.92-23.9$ \\
\hline Retinopathy* & 1.78 & 0.62 & 0.004 & 5.92 & $1.75-20.09$ \\
\hline Nephropathy & 0.67 & 0.06 & 0.26 & 1.9 & $0.59-6.39$ \\
\hline Neuropathy & 0.7 & 0.1 & 0.87 & 1.1 & $0.28-4.45$ \\
\hline Hypoglycaemia & 0.97 & 0.05 & 0.1 & 2.65 & $0.82-8.51$ \\
\hline Insulin & 0.9 & 0.6 & 0.11 & 2.7 & $0.78-9.44$ \\
\hline OAD & 0.56 & 0.02 & 0.07 & 1.45 & $1.2-1.54$ \\
\hline Family history of diabetes & 0.45 & 0.06 & 0.45 & 1.5 & $0.47-5.13$ \\
\hline Co-morbidity (n)* & 0.25 & 0.1 & 0.01 & 1.28 & $1.05-1.57$ \\
\hline $\mathrm{CHOL}(\mathrm{mmol} / \mathrm{l})$ & 0.1 & 0.01 & 0.98 & 1.00 & $0.98-1.01$ \\
\hline LDL (mmol/l) & 0.01 & 0.007 & 0.47 & 1.007 & $0.98-1.02$ \\
\hline TG (mmol/l/)* & 0.025 & 0.006 & $<0.001$ & 1.025 & $\begin{array}{l}1.012- \\
1.038\end{array}$ \\
\hline $\mathrm{HDL}(\mathrm{mmol} /)^{*}$ & -0.08 & 0.02 & 0.003 & 0.924 & $0.87-0.97$ \\
\hline BMI (kg/m2) & 0.3 & 0.08 & 0.66 & 1.04 & $0.88-1.21$ \\
\hline Systolic blood pressure $(\mathrm{mm} \mathrm{Hg})$ & 0.03 & 0.01 & 0.11 & 1.03 & $0.99-1.07$ \\
\hline Diastolic blood pressure $(\mathrm{mm} \mathrm{Hg})$ & -0.03 & 0.01 & 0.62 & 0.98 & $0.92-1.05$ \\
\hline $\begin{array}{l}\text { Fasting plasma glucose } \\
(\mathrm{mmol} / \mathrm{l})^{*}\end{array}$ & 0.09 & 0.02 & $<0.001$ & 1.09 & $1.03-1.15$ \\
\hline MoCA score* & -0.57 & 0.2 & 0.006 & 0.57 & $0.37-0.85$ \\
\hline
\end{tabular}

MoCA score*

$B$ - regression coefficient; $\mathrm{Cl}$ - confidence interval for odds ratio; $\mathrm{OR}$ - odds ratio; $\mathrm{SE}$ - standard error; *significance $-\mathrm{p}<0.05$.

education, higher nunber of visits to a doctor per year, increased number of co-morbidities, presence of CVD, retinopathy, higher levels of triglycerides and fasting glucose, lower level of HDL cholesterol, and a lower MoCA score. It is possible that poor glycaemic control in MCI subjects could be explained by more advanced and longer duration diabetes with associated other co-morbidities. Persistent hyperglycaemia and long duration of diabetes are both associated with an increased development of cognitive impairment, as in the presence of vascular risk factors 
and microvascular or macrovascular complications [29].A longitudinal study has shown that general cognitive ability was significantly lower in people with moderate-to-severe diabetic retinopathy than in those without retinopathy [30]. In the current study, the presence of retinopathy increased the likelihood of having poor glycaemic control in MCI subjects.

Education level is a well-known factor strongly related to cognitive function. Other studies have revealed that diabetic subjects with lower levels of education have more long-term complications, more cardiovascular diseases and a greater risk of mortality [31]. Statins can also influence cognitive performance in diabetic patients. The literature, however, provides contradictory results. Some studies report no statinrelated reduction in incident dementia, while others showed a protective effect of statins against incident and worsening dementia [32]. The current analyzed other treatments (including statins), but no differences were noticed between groups.

In the multivariable model in the presented study, fasting blood glucose and higher levels of triglycerides were also independent predictors of poor diabetes control in MCI patients. High FBG was associated with dysregulated endogenous glucose production, and with subsequent glucotoxicity, lipotoxicity and failure of beta cells. Data from different studies have given contradictory results about the relationship of fasting plasma glucose with cognitive impairment. In one cross-sectional study on elderly diabetics, the authors observed an 'inverted- $U$ ' relationship between FPG (range $47-366 \mathrm{mg} / \mathrm{dl}$ ) and performance on two tests: Modified Mini-Mental State Examination (3MS) and the Digit Symbol Substitution Test (DSS) [33]. Two other studies reported that higher glucose levels may be a risk factor for dementia, even among persons without diabetes [34, 35]. Opposite to these results, the ACCORD-MIND baseline analysis did not observe a relationship between fasting blood sugar and cognitive impairment [24]. A higher level of triglycerides is also a factor associated with poor glycaemic control in MCI patients. This result is consistent with other studies which have focused on hypertriglyceridaemia and its relationship with dementia [36, 37].

The presented study did not find that poor glycaemic control in MCI patients could be explained by difficulties in diabetes self-management behaviour. However, some executive functions could be important for perform complex tasks required for self care, such as blood glucose monitoring and, dietary modification and regular physical activity. One study revealed that in older adults, executive dysfunction detected by objective tests is associated with poor glycaemic control [38]. Impairments in executive function are associated with poor adherence to medication, low independence or instrumental activities of daily living, and low autonomy and inability to make decisions.

Limitations of the study. The study has two principle limitations:

1) it was a single-centre study with a small sample size; it must therefore be emphasized that the conclusions should be interpreted more carefully if transposed into a larger population.

2) The study was not designed as a longitudinal prospective investigation. It could be interesting to check the achievements of the aims of therapy after modification of risk factors. Nevertheless, this is the first study to evaluate mild cognitive dysfunction in elderly patients with type 2 diabetes in Poland, and to correlate it with diabetes control.

\section{CONCLUSIONS}

The study shows that there is a high prevalence of poor glycaemic control among elderly diabetics with MCI. Fewer years of education, a higher number of visits to a doctor per year, increased number of co-morbidities, presence of CVD, retinopathy, higher levels of triglycerides and fasting glucose, lower level of HDL cholesterol, and a lower MoCA score, are the factors associated with poor glycaemic control in the examined patients. Higher plasma levels of fasting glucose and triglycerides seem to be the most important predictors of poor glycaemic control. Given the high prevalence of diabetes in older adults and co-morbid cognitive impairment, further prospective studies are needed to elucidate these relationships.

\section{Conflict of Interest}

The authors declare that they have no conflict of interest.

\section{Funding Statement}

The study was supported by a non-profit grant from the Medical University in Lodz (No. 503/8-072-04/503-81-001).

\section{REFERENCES}

1. Ogurtsova K, da Rocha Fernandes JD, Huang Y, Linnenkamp U, Guariguata L, et. al. IDF Diabetes Atlas: Global estimates for the prevalence of diabetes for 2015 and 2040. Diabetes Res Clin Pract. 2017; 128: 40-50. https://doi.org/10.1016/j.diabres

2.Xue M, Xu W, Ou YN, Cao XP, Tan MS, Tan L, et al. Diabetes mellitus and risks of cognitive impairment and dementia: A systematic review and meta-analysis of 144 prospective studies. Ageing Res Rev. 2019; 55 : 100944. https://doi.org/10.1016/j.arr.2019.100944

3. Black S, Kraemer K, Shah A, Simpson G, Scogin F, Smith A. Diabetes, Depression, and Cognition: a Recursive Cycle of Cognitive Dysfunction and Glycemic Dysregulation.Curr Diab Rep. 2018; 18: 118. https://doi. org/10.1007/s11892-018-1079-0.

4. Petersen RC, Roberts RO, Knopman DS, Boeve BF, Geda YE, Ivnik RJ, et al. Mild cognitive impairment: ten years later. Arch Neurol. 2009; 66: 1447-1455. https://doi.org/10.1001/archneurol.2009.266

5. Hermida AP, McDonald WM, Steenland K, Levey AT. The association between late-life depression, mild cognitive impairment and dementia: is inflammation the missing link? Expert Rev Neurother. 2012; 12: 1339-1350. https://doi.org/10.1586/ern.12.127

6. Gorska-Ciebiada M, Saryusz-Wolska M, Borkowska A, Ciebiada M, Loba J. Serum levels of inflammatory markers in depressed elderly patients with diabetes and mild cognitive impairment. PLoS ONE 2015; 10(3): e0120433. https://doi.org/10.1371/journal.pone.0120433

7. Hosny SS, Bahaaeldin AM, Khater MS, Bekhet MM, Hebah HA, Hasanin GA. Role of Inflammatory Markers in Elderly Type 2 Diabetic Patients with Mild Cognitive Impairment.Curr Diabetes Rev. 2019; 15: 247-253. https://doi.org/10.2174/1573399814666180423113341

8. Serlin Y, Levy J, Shalev H. Vascular pathology and blood-brain barrier disruption in cognitive and psychiatric complications of type 2 diabetes mellitus. Cardiovasc Psychiatry Neurol. 2011; 2011: 609202. https://doi. org/10.1155/2011/609202

9. Xu W, Qiu C, Gatz M, Pedersen NL, Johansson B, Fratiglioni L. Mid- and late-life diabetes in relation to the risk of dementia: a population-based twin study. Diabetes. 2009; 58(1): 71-77.

10. Messier C. Impact of impaired glucose tolerance and type 2 diabetes on cognitive aging. Neurobiol Aging. 2005; 26(Suppl 1): 26-30.

11. de Wet H, Levitt N, Tipping B. Executive cognitive impairment detected by simple bedside testing is associated with poor glycaemic control in type 2 diabetes. S Afr Med J. 2007; 97(11): 1074-1076. 
12. Munshi M, Grande L, Hayes M, et al. Cognitive dysfunction is associated with poor diabetes control in older adults. Diabetes Care. 2006; 29(8): 1794-1799.

13. Gorska-Ciebiada M, Saryusz-Wolska M, Ciebiada M, Loba J. Mild cognitive impairment and depressive symptoms in elderly patients with diabetes - prevalence, risk factors and co-morbidity. J Diabetes Res. 2014; 179648. https://doi.org/10.1155/2014/179648

14. Nasreddine ZS, Phillips NA, B'edirian V, Charbonneau S, Whitehead V, Collin I, et al. The Montreal Cognitive Assessment, MoCA: a brief screening tool for mild cognitive impairment. J Am Geriatr Soc. 2005; 53: 695-699.

15. Katz S, Downs TD, Cash HR, Grotz RC. Progress in development of the index of ADL. Gerontologist 1970; 10: 20-30.

16. Lawton MP, Brody EM. Assessment of older people: self-maintaining and instrumental activities of daily living. Gerontologist 1969; 3: 179-86.

17. Alagiakrishnan K, Zhao N, Mereu L, Senior P, Senthilselvan A. Montreal Cognitive Assessment is superior to standardized Mini-Mental Status Exam in detecting Mild Cognitive Impairment in the middle-aged and elderly patients with type 2 diabetes mellitus. Biomed Res Int. 2013; 2013: 186106. https://doi.org/10.1155/2013/186106

18. Petersen RC. Mild cognitive impairment as a diagnostic entity. J Intern Med. 2004; 256: 183-194.

19. Portet F, Ousset PJ, Visser PJ, Frisoni GB, Nobili F, Scheltens P, et al. Mild cognitive impairment (MCI) in medical practice: a critical review of the concept and new diagnostic procedure. Report of the MCI Working Group of the European Consortium on Alzheimer's Disease. J Neurol Neurosurg Psychiatry 2006; 77: 714-778.

20. American Diabetes Association. Standards of medical care in diabetes 2014. Diabetes Care 2014; 37: S14-80.

21. Strachan MW. D Lawrence Lecture 2010. The brain as a target organ in Type 2 diabetes: exploring the links with cognitive impairment and dementia. Diabet Med. 2011; 28: 141-147. https://doi.org/10.1111/j.14645491.2010.03199.x

22. Rawlings AM, Sharrett AR, Albert MS, Coresh J, Windham BG, Power MC, et al. The Association of Late-Life Diabetes Status and Hyperglycemia With Incident Mild Cognitive Impairment and Dementia: The ARIC Study. Diabetes Care. 2019; 42: 1248-1254. https:// doi.org/10.2337/dc19-0120

23. Umegaki H, Hayashi T, Nomura H, Yanagawa M, Nonogaki Z, Nakshima $\mathrm{H}$, et al. Cognitive dysfunction: An emerging concept of a new diabetic complication in the elderly Geriatr Gerontol Int 2013; 13: 28-34. https:// doi.org/10.1111/j.1447-0594.2012.00922.x

24. Cukierman-Yaffe T, Gerstein HC, Williamson JD, Lazar RM, Lovato L, Miller ME, et al. Relationship between baseline glycemic control and cognitive function in individuals with type 2 diabetes and other cardiovascular risk factors. The Action to Control Cardiovascular Risk in Diabetes-Memory in Diabetes (ACCORD-MIND) trial. Diabetes Care 2009; 32: 221-226. https://doi.org/10.2337/dc08-1153

25. Umegaki H, Kawamura T, Mogi N, Umemura T, Kanai A, Sano T. Glucose control levels, ischaemic brain lesions, and hyperinsulinaemia were associated with cognitive dysfunction in diabetic elderly. Age Ageing 2008;37:458-461. https://doi.org/10.1093/ageing/afn051.

26. Yaffe K, Blackwell T, Whitmer RA, Krueger K, Barrett Connor E. Glycosylated hemoglobin level and development of mild cognitive impairment or dementia in older women. J Nutr Health Aging 2006; 10: $293-295$.

27. Imamine R, Kawamura T, Umemura T, Umegaki H, Kawano N, Hotta $\mathrm{M}$, et al. Does cerebral small vessel disease predict future decline of cognitive function in elderly patients with type 2 diabetes? Diabetes Res Clin Pract. 2011; 94: 91-99. https://doi.org/10.1016/j.diabres.2011.06.014

28. Grober E, Hall CB, Hahn SR, Lipton RB. Memory Impairment and Executive Dysfunction are Associated with Inadequately Controlled Diabetes in Older Adults. J Prim Care Community Health 2011; 2: 229-233. https://doi.org/10.1177/2150131911409945

29. Reijmer YD, van den Berg E, Ruis C, Kappelle LJ, Biessels GJ. Cognitive dysfunction in patients with type 2 diabetes. Diabetes Metab Res Rev 2010; 27: 195-202. https://doi.org/10.1002/dmrr.1112

30. Ding J, Strachan MW, Reynolds RM, Frier BM, Deary IJ, Fowkes FG, et al. Diabetic retinopathy and cognitive decline in older people with type 2 diabetes: the Edinburgh type 2 diabetes study. Diabetes 2010; 59: 2883-2889. https://doi.org/10.2337/db10-0752

31. Dray-Spira R, Gary TL, Brancati FL. Socioeconomic position and cardio-vascular disease in adults with and without diabetes: United States trends,1997-2005. J Gen Intern Med. 2008; 23: 1634-1641.

32. Singh S, Zieman S, Go AS, Fortmann SP, Wenger NK, Fleg JL, et al. Statins for Primary Prevention in Older Adults-Moving Toward Evidence-Based Decision-Making. J Am Geriatr Soc. 2018; 66: 21882196. https://doi.org/doi: 10.1111/jgs.15449

33. Shorr RI, de Rekeneire N, Resnick HE, Yaffe K, Somes GW, Kanaya AM, et al. Simonsick EM. Glycemia and cognitive function in older adults using glucose-lowering drugs. J Nutr Health Aging 2006; 10: 297-301.

34. Crane PK, Walker R, Hubbard RA et al. Glucose levels and risk of dementia. N Engl J Med. 2013; 369: 540-548.

35. Kerti L, Witte AV, Winkler A et al. Higher glucose levels associated with lower memory and reduced hippocampal microstructure. Neurology 2013; 81: 1746-1752.

36. Raffaitin C, Gin H, Empana JP, Helmer C, Berr C, Tzourio C, et al. Metabolic syndrome and risk for incident Alzheimer's disease or vascular dementia: the Three-City Study. Diabetes Care 2009; 32: 169-174. https://doi.org/10.2337/dc08-0272

37. Rouch I, Trombert B, Kossowsky MP, Laurent B, Celle S, Ntougou Assoumou G, et al. Metabolic syndrome is associated with poor memory and executive performance in elderly community residents: the PROOF study. Am J Geriatr Psychiatry 2014; 22: 1096-104. https:// doi.org/10.1016/j.jagp.2014.01.005

38. Munshi MN, Hayes M, Iwata I, Lee Y, Weinger K. Which aspects of executive dysfunction influence ability to manage diabetes in older adults? Diabet Med. 2012; 29: 1171-1177. https://doi.org/10.1111/j.14645491.2012.03606.x 